This is the author's accepted manuscript of the following article: Simpson, R., Sturges, J. \& Weight, P. (2009), "Transient, unsettling and creative space: Experiences of liminality through the accounts of Chinese students on a UK-based MBA, Management Learning, 41(1), 53-70, doi:

$10.1177 / 1350507609350830$, which has been published in final form at http://mlq.sagepub.com/content/41/1/53.

\title{
Transient, Unsettling and Creative Space: Experiences of Liminality through the Accounts of Chinese Students on a UK based MBA
}

\author{
Ruth Simpson, Brunel University \\ Email: ruth.simpson@ brunel.ac.uk \\ Jane Sturges, Kings College \\ Pauline Weight, Cranfield University
}

\begin{abstract}
This article explores the experiences of liminality through the accounts of Chinese students on a UK based MBA programme. The transient nature of the MBA experience, as well as the inter-national status of the Chinese student, is resonant with conceptualisations of liminality as 'in between' space. Based on semi-structured interviews with twenty MBA graduates who had subsequently returned to China with their qualification, we explored their perceptions of outcomes from the course and their experiences as international students. Results support the unsettling yet creative implications of liminality, as well as fragmented insecure nature of identities, as individuals pass through the MBA 'rite of passage' in terms of 'becoming' a manager and entering a new phase of career. Accounts suggest the creation of hierarchical structures within liminal space whereby Chinese students, through their positioning at the margin, have uncomfortable yet illuminating encounters with alterity. At the same time, they experience levels of ambiguity and uncertainty in the post-liminal phase of China located employments, as new Western based managerial identities collide with dominant discourses of Chinese organization.
\end{abstract}

Key words: liminality, MBA, China, identity 


\section{Introduction}

This paper draws on the concept of liminality to explore the experiences of Chinese MBA graduates who had studied in the UK and who subsequently returned to China with their qualification. The importance of liminality has emerged in recent accounts of organizational life, largely reflective of changes in an employment relationship increasingly characterised by outsourcing, by temporary contractual arrangements and by consultancy work. Liminality here refers to occupancy of 'in between' spaces (Turner, 1977; Garsten, 1999) where individuals are neither wholly part of nor wholly divorced from the organization. The concept has been used to highlight the unsettling nature of these spaces and the ambiguities that can accrue. In this paper, we argue that liminality can usefully be applied to the MBA. We accordingly draw on the concept to examine the implications of the 'in between' status of the MBA student in their 'rite of passage' to a management career as well as the spaces of 'inter-culturality' for the experiences and subjectivities of Chinese MBA graduates who studied in the UK and who are consequently exposed to Anglo-American assumptions about management practice. By drawing on the concept of liminality, we throw light on the complex nature of outcomes from the MBA - outcomes that we argue go beyond the acquisition of knowledge and skills to include identity effects of a process of development and change, transformations and creativity as individuals negotiate tensions and ambiguity as well as the implications of differentiated locations within liminal space.

These understandings are particularly pertinent given the large increase in numbers of Chinese students who attend UK based management education programmes. Nearly one quarter of management students now come from outside the UK with China one 
of the most numerous (Association of Business Schools, 2007). Specific figures here This rise reflects a growing shortage of managerial talent in China (Ahlstrom, Bruton and Chan, 2001) - and of Chinese based MBA providers (Tjosvold and Ding, 2001; Tang and Ward, 2003). While the number of providers in China has increased, from the original nine in the early 1990s to over eighty today, shortages of quality programmes mean that many students travel abroad to study for the MBA. In this respect, in the current study the opportunity to learn English, to attend a prestigious university and to have a 'foreign experience' - seen as particularly advantageous in reformed China - emerged as key motivating factors in Chinese students' choice of their UK based MBA.

The voices of these students, as Currie (2007) has pointed out, have often been marginalised leaving room to further explore the ways in which diverse cultural characteristics interact with the Anglo-American assumptions embedded within the pedagogy of the MBA. Through the concept of liminality - reflective of the transient and inter-national status of the Chinese MBA studentship - this paper seeks to understand some of these experiences and explores how Chinese graduates, reflecting back, perceive the benefits and outcomes of the course. Some experiences of liminality (e.g. the 'in between' status of study in terms of future and previous career) may be common to all students. However, as suggested above, the position of international students generally and Chinese students in particular may well differ from their Western counterparts in that both geographical and socio-cultural dislocations are involved during the former's period of study - leading to, from Sturdy and Gabriel (2000), an 'added ambivalence' to their experience of the course. This makes the study of Chinese students who subsequently return to their country of 
origin of particular interest - both in terms of the general need to develop a greater understanding of the tensions and dynamics involved as international students encounter a Anglo-American pedagogy and in terms of their specific experience of liminality, throwing light on the implications of these 'in between spaces' within the context of the MBA.

The paper is organized as follows. After discussing the significance of work on liminality and liminal identities both in a general context and with specific reference to the MBA, we set out the method adopted in the study. We then present the findings which are organized around the MBA as an experience of transience and change, the role of the MBA in creating the identity of manager and the significance of spaces in the margin for the experience of Chinese students. These highlight the diverse nature of perceived outcomes from the course as students describe in both positive and negative terms the value they believed they had gained. We conclude by highlighting, in accordance with existing work, the transient, unsettling and creative aspects of this liminal space. At the same time, we point to the differentiated dimensions of this space and the potential for aspects of liminality to 'seep' into the post-liminal phase. We argue that, through the lens of liminality, a more complex account of the MBA experience and some of the outcomes from the course can be gained.

\section{Liminal Spaces, Liminal Identities}

The blurring of organizational boundaries has been the focus of much organizational research - with attention drawn to the flattening of hierarchies and the instabilities and uncertainties within current non-standard employment contracts. Many employees therefore find themselves on the margins or occupying 'in between' spaces where normal rules of organizational engagement are woolly, blurred or do not apply. 
While some categories of workers can be clearly identified as occupiers of such space (e.g. those who work from home), others can be seen as 'passing through'. Turner (1977) has focused on the temporary or transitional nature of this space as individuals find themselves 'temporarily undefined' in between social orders as they move from one phase to another. Separated from an existing social order and from their previous experience, individuals thus become temporarily incorporated into another only to subsequently move on (Sturdy et al, 2006a).

Eriksson-Zetterquist (2002) has classified these orders as 'preliminal rites', whereby individuals separate - often both geographically and symbolically - from earlier positions and roles, and 'postliminal rites' which capture the ceremonies of incorporation and belonging into the new world. In between lies the liminal phase of transition where an individual has left his or her earlier role but has not yet acquired the new one - a phase characterised by ambiguity since, from Turner (1977), they are beyond the normative social structure with little or no access to 'schemes of classification' that indicate one's position in a cultural space (Eriksson-Zetterquist, 2002). Liminality can thus be seen as a transition from one status to another (Czarniawska and Mazza, 2003) or as a 'limbo of statuslessness' (Turner, 1977) on a journey towards new roles and understandings.

This has implications for the way individuals experience the organization and for subjectivities through blurred, ambiguous or transitional identities (Sturdy et al, 2006). Rather than a fixed attribute of the individual, identity here is conceptualised as fragmented and 'in process'. From this perspective, identity is a constant and emergent project (Sveningsson \& Alvesson, 2003; Whitehead, 2001; Kerfoot and 
Knights, 1998) and an aspect of relational and situated processes (Pullen, 2006). In the latter respect, recent work (e.g. Halford and Leonard, 2006; Massey, 2005) has highlighted the ways in which place and space are implicated in subjectivity - both as a manifestation of hierarchical relations that influences identity and as a resource from which to construct a comfortable sense of self.

On this basis, liminal spaces can contribute to a sense of uncertainty over identities, positions and routines as individuals find themselves divorced from existing structures and known ways of 'doing and being'. These uncertainties and ambiguities may be exacerbated by the frequent siting of such space in the margins - tainted by low status and exclusion. Perhaps in response, as Czarniawaska and Mazza (2003) point out, individuals may experience a heightened sense of belonging and togetherness with others who share the same liminal space. From Turner (1977), individuals can experience 'unstructured communitas' with others similarly positioned, oriented not around hierarchical differentiation as in a structured community, but around comradeship and undifferentiated homogeneity - features that can be intensified during periods of unpredictability (Eriksson-Zetterquist, 2002; Tempest and Starkey, 2004). Finally, liminal spaces may lead to a sense of autonomy and personal freedom as individuals transcend organizational constraints. Such space may enhance opportunities for creativity as, unbound by structural procedures (Garsten, 1999; Clegg et al, 2004), individuals challenge existing boundaries (Sturdy et al, 2006a) so fostering deviation and originality (Turner, 1977).

\section{Liminality, the MBA and Outcomes from the Course}

The temporary and transitional aspects of liminality, together with the potential for the above identity effects, have resonance with the MBA. In the first instance, MBA 
students can be seen to be in between social states. Many business schools (and the programme that forms the basis of this study in particular) expect students to have some preliminary management experience before they come on the course. The MBA programme thus occupies a space between two relatively fixed employment positions. Separate from earlier lives, students occupy a transitional space on the MBA before moving back into the labour market and experiencing a new belonging in what is invariably a more senior role. From Turner (1982), they are thus in a space that lies in between social structures, between 'preliminal' and 'postliminal' rites (ErikssonZetterquist, 2002) representative of a transition from one status to another in the process of 'becoming' a manager. Characteristic of this position is a lack of familiarity, a known order or predictability in terms of continuity at work (Garsten, 1999). In the context of the MBA, students must learn new systems and procedures (e.g. group work expectations and practices; regulations concerning the completion and submission of assignments) in which previously acquired systems of classifications or routines do not apply.

This liminality may be further enhanced by the 'in between' nature of the status of Chinese MBAs who have travelled to the UK to undertake their management education and who must learn and assimilate different cultural practices and understandings. For example, as Sturdy and Gabriel (2000) point out, tensions and ambiguities can occur as Western pedagogies based on competitive individualism and questioning of beliefs collide with Confucian respect for authority and harmony within the group. International students generally can be marginalised and silenced by expectations of pro-activity within the classroom (debating, interrupting, questioning), which can violate norms of politeness, respect and reciprocity (Currie, 2007; Holmes, 
2004; Choo, 2007). Group work, a key arena for MBA teaching and learning, can raise particular problems as activities of critical analysis and dialogue come into conflict with a more prescriptive approach adopted in China based on a less critical acceptance of teacher authority (Currie and Knights, 2003; Currie, 2007). Through this trans-cultural encounter and through 'transversality' (Schrag, 1997; Welsch, 1999), such students must therefore navigate a landscape that is characterised by difference as well as by transience and temporality. As Sturdy et al (2006a) argue these spaces raise key questions about identity. Chinese students as 'individuals in motion' and experiencing temporary homelessness, must adjust to new conditions and encounters. In liminal terms, Chinese students cross and are located between physical geographical as well as cultural boundaries - suspended between social structures (Turner, 1982) that have material as well as ontological implications.

On similar lines to Eriksson-Zetterquist (2002) who explored liminality through an inhouse management training programme (highlighting features such as marginality and feelings of community), we argue from the above that the concept can be usefully applied to the MBA. This may help to provide a more nuanced understanding of the processes involved in this year of development and change. Current work on MBA outcomes has focussed largely on the career effects and the nature of skills and knowledge supposedly developed in the course. Such skills have often been critiqued as being 'out of step' with the modern world. For example, it has been suggested that programmes focus too much on 'hard' analytical capabilities (e.g. data analysis, financial control) to the neglect of 'softer' skills (e.g. communication, negotiation, listening skills) seen as increasingly important in the work place (Kretovics, 1999; Mintzberg \& Gosling, 2002; Pfeffer \& Fong, 2002; Simpson, 2000; Simpson et al, 
2005). Work in the context of China also indicate a value placed on 'hard' skills from the course with a priority afforded to production, $\mathrm{R} \& \mathrm{D}$, finance and engineering to the neglect of behaviorally oriented and more culturally specific areas such as marketing strategy, training and HRM (McLean and Shi, 2000; Haight and Kwong, 2000; Fan, 1998; Alon and McIntyre, 2005). In a study comparing outcomes from MBA programmes in China with those from the UK, Ituma et al (2007) for example found that Chinese students perceived gains in particular from 'hard functional' skills ( $R \& D$, innovation, finance and accountancy) rather than from personal (confidence, credibility) and interpersonal (leadership, communication) skills valued in the UK.

Recent work (e.g. Grey, 2002; 2004; Sturdy et al, 2006b; Sinclair, date; Simpson, 2006; Currie and Knights, 2003) has turned to more processual aspects of the MBA experience - in the form, for example, of the values and discourses embedded in the MBA. Here, the assumed neutrality of management education is problematised, and the 'hidden' values of, in particular, managerialism, instrumental rationality and neoimperialism are highlighted (French \& Grey, 1996; Grey \& Mitev, 1995; Sturdy and Gabriel, 2000; Currie and Knights, 2003). These values privilege managers' views over those of other groups (Watson, 2001; Chia, date), promote the application of management techniques to diverse organizational problems that largely concern an unreflective search for control (Grey et al, 1996; Grey, 1996; 2004) and prioritize a Western based model of management practice and management education pedagogy (Currie, 2007; Currie and Knights, 2003; Sturdy and Gabriel, 2000; Choo, 2007; Clegg, date). From this, the implications of the MBA experience and qualification for the construction of managerial identities and the influence of the MBA on the 'performance of manager' have been explored (Grey (2002; 2004; Sturdy et al, 
2006b). Grey for example has suggested that the MBA serves to socialize students into a particular set of morals, ethics and ideals based largely around managerialism, individualism and instrumental rationality while Sturdy et al (2006b) have pointed to the performative nature of the language acquired through the course thus helping to construct, through credible performances, a (managerial) self. These values have profound implications for international students who, as we have seen, must navigate between a philosophy of supposed 'best practice' that favours Western managing and organizing and their own norms, identities and practices. Sturdy and Gabriel (2000) for example have pointed to the tensions between a generalized faith in Western management ideas among Malaysian MBA students and resistance to their neoimperialist overtones and perceived lack of relevance to their own cultural contexts. In a similar vein, Currie (2007) and Choo (2007) have highlighted some of the experiences and emotions (of marginalization and silence; of fear, anxiety and confusion) of Chinese MBA students as they seek to accommodate Anglo-American assumptions and norms. Such work notwithstanding, as Currie (2007) notes, the voice of the international student is often neglected in these tensions, struggles and dynamics.

\section{Method}

Against this background, and with an alignment with the above work on the MBA as a process rather than a purveyor of knowledge and skills, this study set out to explore how Chinese MBAs experience and navigate the 'in between' spaces of this period of development. Accounts of liminality were accessed through a discussion of their MBA experience and their perceptions of outcomes from the course. Graduates were asked about their motives for taking the course, their career history and career progress. In addition they were asked to reflect on the nature of outcomes - the 
skills/benefits they valued most and those which had been most useful to them in their post-graduate (China based) careers. Interviews also explored more broadly their experiences as international students - how they managed cultural difference, their experiences of group work and their most difficult or challenging encounters.

Through these accounts, respondents explored issues relating to transformation and change, to mobility and dislocation and to interculturality.

The sample was established through the alumni association of a well established international MBA provider in the UK. All respondents - 13 men and 7 women were Chinese nationals who had come from China to the UK to undertake their MBA and who had subsequently returned to their homeland. Each had been back in China with their qualification for between 6 months and two years. The majority (14 graduates) had effected a career change since acquiring the MBA, four had been promoted within their exisitng organization and two were still seeking work. Of those in employment, all were in senior management positions in foreign owned enterprises or in Chinese owned enterprises with some global connnections. Two were at vicepresident level.

All interviews took place in China - either in Beijung or Shanghai - and lasted for approximately one hour, giving respondents the opportunity to reflect on MBA outcomes and experience. The three named authors conducted the interviews in two specific locations (both hotels) in Shanghai and Beijing. In order to gain an 'authentic' understanding of graduates' perceptions of outcomes from the MBA and of their overall MBA experience (Silverman, 1993), semi-structured interviews were used where certain themes (e.g. career history; motives for taking the MBA; 
skills/benefits acquired from the course; experience of working with students from diverse backgrounds) were common to all. After each 'set' of three interviews, authors reflected on and discussed key issues that had emerged so that adjustments could be made to lines of inquiry. Such cross referencing enhanced the scope and depth of data whilst maintaining a focus on the overall research themes.

Reflexivity here

Interviews were recorded and later transcribed. After reading and re-reading transcripts in a process of familiarisation, data was organized around the key themes outlined above with the help of N.U.D.I.S.T. software. These broad 'slices' were then examined and interpreted through the lens of liminality and liminal experiences. This stage of analysis was undertaken by two of the three researchers who discussed emergent themes. Through multiple readings of the data and iteration, agreement was reached concerning interpretation of accounts of liminality and of the MBA experience. The aim was thus to produce analytical insights rather than generalizability. The themes are presented below and relate to the MBA as an experience of transience and change, the MBA as a process of 'becoming' a manager and the encounter with the MBA 'at the margins'.

\section{The MBA as an Experience of Transience and Change}

There's a Chinese phrase - once you stay in a well like a frog you always think the world is just big like this, but once you jump out you say 'ha, this is the world'... that's the feeling I got from (Business School).

(interviewee)

The transient 'in between' as well as the transformative status of the MBA was evident in Chinese graduates' accounts of their experiences. These accounts were often presented in positive terms. Being placed in a strange environment, removed from known structures and procedures and where the 'rules of the game' were unclear 
presented challenges that could provide rich learning opportunities and a broadening of vision as the above quote suggests. Graduates referred to how the strangeness and lack of familiarity with systems and structures contributed to feelings of dislocation and disorientation, which, over time dissipated and formed the basis for development and change. Respondents variously referred to 'new understandings', 'life changing experiences', 'a new way of thinking' as 'old' forms of thought and action were contested and challenged. In this respect, the developmental process involved as individuals adjusted to new conditions and questioned ingrained understandings were common themes:

Before (Business School) my experience was straightforward - college and a local company. You don't think about too much else. When you are placed in a totally different environment, a different situation, you don't have enough experience to work out a way to handle it. The difficulties are maybe more but the way to conquer them also increases confidence.

Many graduates referred to the transformative nature of interpersonal skills acquired (e.g. listening, negotiation, communication) through team-working. As one graduate commented in relation to these skills 'I felt like nothing is impossible'. The value placed on these skills is in contrast to Chinese based approaches to management education, still dominated by a pre-reform legacy of production, $R \& D$, finance and engineering - reflected in Ituma et al's (2007) China based study where students placed value on 'hard' skills from the course. This is set against the relative neglect of behaviourally oriented and more culturally specific areas such as leadership, personal development and HRM (McLean and Shi, 2000; Haight and Kwong, 2000). Being introduced to different perceptions of management and ways of working, particularly in relation to the development of leadership and interpersonal skills, may therefore have intensified feelings of personal growth and change. 
Temporarily released from pressures of work and from Chinese based structures and procedures, the MBA also gave space for self reflection in what one graduate described as a 'risk free' environment. This allowed, as one graduate commented, a 'period of time to think about myself'. As Wahlin (2006) argues, being 'out of place' and adjusting to new conditions can stimulate reflexive capacities and encourage a self questioning that may not come readily in more familiar environments. In a typical comment, one student reflected on his development:

Going to (Business School) made me realise that there's still a long way for me to go. Before that I sometimes I think I'm excellent, so I can do everything and tend to be perfect. But now I realise that there are a lot of things I need to do

The mix of nationalities and the challenges of working in teams with people from different backgrounds were seen to enhance cultural understandings and communication - an outcome that emerged from Tomlinson and Egan's (2002) study of an international MBA. These contributed to the construction and feel of a mobile, 'transcultural' self. Transculturality (Welsh, 1999) captures a dynamic process of unifying that allows - even welcomes - plurality and difference. Respondents valued the ease with which they were able to navigate within and between this new environment, experiencing a 'new belonging' in a global world.

I can present to senior managers or to represent the company to give presentations to shareholders or to international conferences - because during the MBA programme I was exposed to international experience it helped me to understand other cultures better...increased my confidence to work in an international context

The foreign experience....talking with different people from different backgrounds, different cultural backgrounds. Now I understand people better than before 
The transitional nature of the MBA can thus be seen in its developmental rationale as the individual moves from one 'stage' in personal, interpersonal and other skill growth to another. This rite of passage can be fraught with uncertainty as, in Turner's (1977) terms, lack of familiarity means that individuals have little recourse to known structures or procedures - a lack that is likely to be exacerbated by the foreign experience of Chinese MBAs. However, whilst unsettling, many students found the MBA opened up new ways of thinking and gave them the space to self reflect free from existing structures and routines. As Sturdy et al (2006a) point out, while settled organizational identities, routines and rules disappear in liminal spaces, new ones open up. Thus, negotiating uncertainty and overcoming such challenges were frequently identified as a catalyst for development and change, contributing to greater self-awareness and facilitating the uptake of a new mobile, transcultural self.

\section{'Becoming' a Manager}

As a manager you've got to say something or present strategically .. and you've got to present yourself, make yourself look like you have a better understanding of things... and sometimes we've got to make it look good even though you don't have enough information or support from others

interviewee

As Grey (2002) suggests, management education has an important role to play in the creation of the managerial identity and in acquiring the 'skills of appropriate selfhood'. The process of 'becoming a manager' (Bryans \& Mavin, 2000) and of constructing and negotiating a managerial identity is predicated upon daily 'performances' which serve to support, readjust or undermine that identity. As the above quote indicates, management can thus be seen as a performance - what Sturdy et al (2006b) refer to as a 'confidence trick' - which may conceal underlying feelings of uncertainty. 
All respondents referred to the confidence they had acquired from the MBA and how this had influenced in a positive way authenticity of performances in a management role:

For example,... in my daily work when a project comes in, my boss will ask 'can you handle it? How many people do you need? How much time will you need?' So in doing this I can say, okay this is what I can do, what sort of team members I make, I can build a team. So I'm confident. .

For many, the MBA helped to relieve some of the uncertainty and anxiety around the performance of manager - uncertainties that may emanate from ambiguities relating to role expectations (Thomas and Linstead, 2002), the visibility of managerial work and/or the fear of failure (Knights \& McCabe, 2001). Most graduates expressed a feeling of greater comfort and security in their management role. For one manager, enhanced confidence was based on the recognition that good management is about conviction and leadership rather than all round expertise:

It's a way of self belief and being more confident.. at management level you don't really need to be strong at everything but just to have a strong feeling you can make it work

Self awareness combined with greater security and comfort in the role reduced feelings of anxiety - particularly around more senior personnel. As one graduate commented: Before the MBA I was afraid of talking with my managers but today I don't have that feeling. This confidence may be reflective of an importance placed on hierarchy and a respect for age in the Chinese context referred to above (Lockett, 1988). Middle managers in particular have less decision making powers than in Western enterprises. They therefore defer more to authority and experience less autonomy (Tang and Ward, 2004; Sturdy and Gabriel, 2000). As Ahlstrom et al (2001) argue, Chinese managers may lack confidence to speak out, to rely on their 
own judgments, to make independent decisions or to suggest new ideas - all factors that were essential to effective team-working on this UK based MBA. Tensions between Chinese based discourses of respect and deference and those from the West organized around independence and autonomy often led to change:

I communicate with people if I need to and I take initiative. It's interesting because when we worked in a study group people from other countries they spoke more, they contributed more than people from China, so I realise that and I knew that if you are going to succeed you've got to be more proactive.

As students, Chinese men and women must therefore navigate between discourses of deference and initiative, giving priority to the latter in the practices of the MBA. In this respect, the MBA enabled the uptake of a (Western based) managerial identity saturated with discourses of pro-action, initiative and independence. The confidence to 'speak out', an essential ingredient in constructions and performances of a 'successful' manager was facilitated by a language of management acquired through the MBA. As one graduate commented: We talk the same language - not in Chinese but in the MBA language. Facilitated by the MBA and supported by confident deliveries, graduates were thus able to present authentic managerial selves in public arenas and, through processes of self reflection, to feel more comfortable with the 'feel' of the role.

The MBA can thus be seen as part of a process that enables a transition to a status of manager, achieved partly through the facilitation of an uptake of a managerial identity as well as an ability to perform effectively in a managerial role (Grey, 2002; 2004; Simpson, 2006). As Grey (2002) has argued, management education has the function of 'self construction and identity formation' as students cope with the insecurities and identity problems associated with the role (Watson, 2001). Increased confidence - 
both from skills acquired and greater self belief - has emerged as an outcome in other contexts (Simpson, 2000; Simpson et al, 2005; Leeming and Baruch, 1996) and is highlighted by Sturdy et al (2006b) and Grey (2002) as evidence of the function of the MBA in identity formation and in socialising students into a set of 'norms values and behaviours' appropriate to a managerial or professional status.

\section{Reverse Culture Shock and the Post-Liminal Phase}

This concentrated period of development and change, while resulting in a sense of 'belonging' in the management world, could also be the cause of 'postliminal' tensions in the form of a 'reverse culture shock' when graduates returned to China. In this respect, newly acquired Western discourses and practices of management based on pro-activity and initiative often collided with Chinese ways of working based around respect for hierarchies and age and high levels of deference to authority (Lockett, 1988; Tang and Ward, 2003; Currie, 2007). Graduates accordingly complained of needing more autonomy in their post MBA career, of having to 'change back again' and of being 'out of step' with Chinese practices. This led to self questioning and feelings of uncertainty. New found confidence for example could be construed as being too challenging to line managers or overly aggressive:

Sometimes I'm just afraid of ... maybe sometimes I think 'am I over-confident?' Yes I keep on asking myself the same question recently, because I think sometimes I maybe over-performing. .. you need to follow your boss, you can't keep on bargaining or keep on persuading him to do something, sometimes you need to just to take it on and do it!

I became more confident that's one thing. Also they think I became aggressive. You know the Chinese people are normally very polite. The Chinese don't like aggression and not overt authority

One graduate summed up her feeling: 
I thought I was quite used to the (Chinese) environment, I know the people I am working with but the thing is I've changed-the people are not changing but I've changed

By helping to frame appropriate behaviours and values, the MBA may therefore be seen as a transitional process that contributes towards a new post-liminal belonging in terms of a greater sense of security in the assumption and negotiation of a managerial identity and in the performance of a managerial role. However, this post-liminal 'new belonging' (Turner, 1977) may be tension ridden and incomplete. Many Chinese graduates experienced estrangement in their post-MBA careers as dominant values of deference and respect for hierarchy collided with the development of a (Western based) confidence and autonomy. Students thus encountered ambiguity (e.g. as confidence was translated as aggression) and experienced feelings of uncertainty frequently conceptualised as more characteristic of the liminal phase.

More here on post-liminality

\section{Spaces in the Margin}

I was afraid that my colleagues would laugh at me - my language. You feel embarrassed...for example in my first month one of my lecturers ask me a question and I cannot catch his question. I get flushed (sic) because I never encountered this kind of situation. I was quite embarrassed because my colleagues start to look at you and they're waiting for your answer but you cannot answer.

As Garsten (1999) argues, liminal spaces are often marginal in the sense that its occupants lie outside or between permanent organizational structures. This suggests a common experience of being 'outside' contributing, as Turner (1969) has indicated, to a sense of togetherness and lack of differentiation with others who share the space. However, as Sturdy et al (2006a) point out, liminal spaces develop their own norms and routines which may mirror or run parallel to the formal (non-liminal) organization. Thus, with respect to the MBA, course activities are often organized to 
simulate the business world where students in groups must complete a task to be assessed as part of the programme. While all MBAs share the same status (as student) and credentials (entry requirements of the course), work on MBA pedagogies have attested to the competitive and hierarchical nature of relations within and between such groups (e.g. Sinclair, 1995; Simpson, 2000).

In this respect, and contrary to earlier accounts where groups were perceived as a source of inter-cultural learning and international capabilities, Chinese graduates described how they were often on the edge of group dynamics as lines of demarcation were quickly formed. Here students were under pressure to produce work of good quality and on time. Discussions as to how to proceed with the task were fast and sometimes heated, based on the ability to be critical and challenge others' ideas. As Currie (2007) has argued, these processes can collide with Chinese values of deference, politeness and modesty, leading to a minimization of self expression as students avoid actions that could lead to criticism or embarrassment (Warden et al, 2005)

At the beginning we tend to remain silent for a long time...we don't like to argue during a presentation I like to wait my turn to talk about my view but the English students tend to interrupt others' speeches but we have to get accustomed to that ... and one of the female student she got very angry with me and said why don't you contribute.

While, as Lockett (1988) and Shi (2001) point out, the Chinese have a group rather than an individual orientation with success likely to be seen as a group enterprise rather than an individual achievement, language difficulties and fear of making mistakes meant Chinese student were often silent in group activities. Similar outcomes have emerged from other studies (e.g. Curries, 2007; Tomlinson and Egan, 2002; Sturdy and Gabriel, 
2000; Warden et al, 2005). Tomlinson and Egan (2002) for example found that confident English speakers were warranted 'dominant voices' early in the course and that (lack of) language capabilities contributes to the creation of an Other as more proficient MBA students excluded those seen to have language difficulties.

As Turner (1982) argues, liminal people are capable of upsetting normative orders and the anger expressed by the non-Chinese student in the quote above may point to perceptions of silence as 'freeloading' and an inversion of norms of contribution and reciprocity associated with group routines. For this particular group of Chinese students, location in the margins was an unusual and uncomfortable experience. Most, if not all, came from prosperous families who were able to afford the large fees and accommodation costs of a year abroad. Confident and part of the 'mainstream' in China, subordinate identities through an Other status impressed painfully on identities.

I was always centre stage in China because a lot of people say 'you are so young, you are very successful, you are a wise guy' or something like that obviously some people hate me - but whether they like me or hate me they really put me centre stage. But in (Business School) for various reasons, I was just on the edge of the stage and always being forgotten.

At first, yes it was a disaster for me - I was always a strong guy in my team (at work), but in the MBA programme especially in terms one and two, Ifeel quite frustrated because of my language capability, because of the teaching style, because of the cultural background, because of a lot of different things Ifeel so frustrated

Yes, the weakest link of the team! I really feel frustrated that I couldn't catch up in certain areas in short time and sometimes my response is not proper, not right.

As Wahlin (2006) points out, entering into a dialogue with the other can 'illuminate the shadows of our own identity' (266). In this respect, living 'in exile' can extend our capacities to see ourselves through the eyes of others, creating opportunities for reflexivity. In this process, referred to by Schrag (1997) as 'radical alterity', cultural 
sensitivity and respect for others combine with critical accounts and analyses of self. Understanding of Other and an ability to engage with the margin, rendered visible through engagement with alterity, were presented by some MBAs as an outcome of their subordinate status:

So I kept thinking, there are always a lot of people who are ... on the outside. I almost always have ignored them - but they are still ... you cannot say they are not wise, they are not a success just because of the time and the opportunity or other things, so you cannot ignore them, they are still-maybe some of them, most of them are very wise and are working very hard.. so they earn my respect..

This included a new found capacity for listening and empathy with junior colleagues:

Before (Business School) I wasn't very good, how do you say, at gentle things. When junior people came to talk with me sometimes I'd just ignore them, but now I will not do it any more. I will listen to them carefully and then try to interpret some other things that...they could not just describe. So I will care about that very much.

Liminality associated with a UK based MBA accordingly impressed subordinate identities and Other status on Chinese students. In this respect, the norms and routines of group work can be seen to partly structure this liminal space so that, far from being undifferentiated as Turner (1977) and more recently Eriksson-Zetterquist (2002) suggest, can have hierarchies constructed within them. Individuals can thus experience the same liminal space differentially - as highlighted by Chinese students' often marginal position.

Experiences of alterity, positioned against earlier locations within the dominant centre of Chinese based employment, threw up painful but at the same time illuminating encounters with self as well as new understandings of the margin. This has resonance with other studies of the MBA which have suggested that listening to the experiences of those on the margins can "illuminate aspects which are taken for granted by those who are more comfortably embraced within the dominant culture" (Sinclair, 1997: 
314). As Sinclair argues, the experience of being in the minority can cultivate a consciousness about the politics of self those situated in the mainstream may be slower or more resistant to understand. Moreover, as Ohlott, Ruderman and McCauley (1994) suggest, meeting challenges and overcoming obstacles - what Mezirow (1991) refers to as 'critical disorienting dilemmas' - can be a powerful developmental and affirming experience. In the context of the MBA, conquering lack of self confidence and coping with pressures and demands from the course itself, as well as from feelings of alienation and marginalisation, may intensify feelings of success and create the conditions for fundamental change.

\section{Conclusion}

This paper set out to explore experiences of liminality through Chinese MBA graduates' accounts of perceptions of outcomes from the course. We have argued that a period of training such as an MBA can be seen as liminal in its transient in-between status as well as in the potentially transformative nature of its results. This liminality is exacerbated for international students who cross cultural boundaries in their year of study. Our work supports existing accounts of liminality -such as those that have explored temporary workers (Garsten, 1999), consultants (Czarniawska and Mazza, 2003) and freelancers (Tempest and Starkey, 2004) - in terms of the evidence to support its transient nature, its inter-structural and ambiguous characteristics as well as some creative but unsettling implications for identities.

The MBA can thus be seen as an exploratory phase (Garsten, 1999) and a 'rite of passage' or 'threshold' (Ulla Eriksson-Zetterquist, 2002) in terms of entering a new stage of career. In Turner's (1977) terms, they are thus 'betwixt and between the positions assigned and arrayed by law, custom, convention and ceremonial' (Turner 
1977: 95). Whereas structure involves systems of thinking and classifications, liminal space - whilst not devoid of structure - opens up possibilities for change as 'old' ways of doing and managing are contested and replaced by new understandings. As Garsten (1999) points out, while new ways of thinking and innovation may take place in established social structures, it is 'at the interfaces and limens' that they most frequently occur (Garsten, 1999: 604). Our results point, along the lines argued by Sturdy et al (2006a), to the unsettling nature of the liminal experience as well as, from Garsten (1999) its potential for creativity as students feel a new belonging in a management role and as they experience a mobile transcultural self . In this respect, Chinese MBA students enter 'new symbolic worlds' replete with possibilities (Turner, 1982). In so doing, they experience sometimes painful tensions as they cross cultural boundaries, negotiate between different discourses of management and organization and as, outside the mainstream, they engage with Other status. In this respect, they recall both positive and negative experiences of the MBA and describe both positive and negative emotions relating to their cross-national MBA 'journey'. While some individual and other variation is likely to emerge, this level of contradiction may be reflective of the 'ambivalence' uncovered by Sturdy and Gabriel (2000) as international students encounter tensions between what is generally seen as 'fashionable', 'modern' and 'effective' Western know-how and their own local understandings and identities.

This paper has added to earlier accounts of liminality in several ways. Firstly, while all MBA students may share some aspects of the experiences of this liminal space (e.g. transience, temporality, passage), there are likely differences in the nature of that experience. This is in contrast to Turner's (1977) view that liminal spaces are 
characterised by homogeneity and an unstructured non-differentiation through a shared sense of alterity in what Garsten (1999) has referred to as a 'hierarchy of territories' that consigns liminal space to the outside. This view has been supported by Eriksson-Zetterquist's (2002) study which found feelings of marginality as well as a sense of togetherness and equality among in-house management trainees. By contrast, Chinese MBAs described a differentiated space in which they were confined in some contexts (e.g. discussions, group work) to the margins - suggesting an over-statement of Turner's (1977) 'unstructured communitas', where comradeship and homogeneity are thought to prevail. As Tomlinson and Egan (2002) found, students from diverse backgrounds can organize around similarity with some groups emerging as more marginal than others. As accounts suggest, boundaries constructed within the MBA suggest the possibility of the creation of structures within and different dimensions of liminal space - as well as to their hierarchical nature.

Secondly, while Turner (1977) conceives of the postliminal phase as a form of "endstate' in that individuals, having passed through the 'limbo of statuslessness', reach a new and higher positioning marked by a sense of belonging, this paper suggests that any such belonging may be incomplete. Chinese graduates may feel a new 'fit' with the elite group of 'manager', assisted by the MBA as a development experience as well as by the credential value of the qualification. However, transformations in self arraigned a round the uptake of a Western based resourceful and independent managerial identity can then collide with previously familiar structures and procedures based on other (e.g. deference to authority, preference for hierarchy) values. As we have seen, this can create ambiguity (a confident performance may be construed as unwelcome aggression), anxiety and a sense of estrangement normally 
associated with the liminal phase. This suggests that the boundaries between liminality and postliminality, while often geographically distinct, may be blurred and permeable as new understandings and identities create disjuncture with once familiar schemes of classification and as experiences and emotions from the liminal phase (ambiguity, anxiety, uncertainty) seep into post-liminarity.

Thirdly, from the above, results throw light on the implications of liminality for the management of identity. The transient nature of this space has suggested blurred and transitional subjectivities as individuals find themselves removed from known structures - as well as possibilities for the creation of a new sense of self. Results from this study give empirical support to the notion of ambiguous, fragmented and creative identities within the liminal space of an MBA that include but go beyond the uptake of a (confident, reliable, decisive) management identity suggested by Grey (2002). Stripped of earlier selfhoods, often aligned with the 'dominant centre' of their previous work and non-work contexts, Chinese students experience the 'opening up' of alternative ways of thinking and being. While welcoming the uptake of a mobile transcultural self and the 'becoming' and new belonging to 'manager', students also experience uncomfortable but illuminating encounters with alterity and ambiguity and uncertainty as new selfhoods collide with dominant discourses at home. In fact, as Sturdy et al (2006b) point out, the very necessity for credible performances of manager, as a form of impression management, suggests their fragility. Thus beneath the performance lie anxiety and insecurity. Overall, this lends empirical support to conceptualisations of the unsettling nature of liminal identities and throws light on the complicated identity effects that can accompany the experience of the MBA. 
Finally, while earlier work has conceptualised liminality as an aspect of the fluidity of organizational boundaries - through for example the flattening of hierarchies and the rise of 'periphery' and/or project and consultancy work, this paper has demonstrated, that the concept can be usefully applied to the MBA. This helps us to move beyond an analysis of the outcomes of the programme in terms of skills acquisition and knowledge gains to consider more complex issues such as the creativity fostered by ambiguities negotiated within liminal space; the identity implications of a liminal process of development and change; and the tensions associated with negotiating unfamiliar structures and procedures. As Sturdy et al (2006b) argue with respect to the MBA, we need to move beyond 'cognitive and utilitarian' views of knowledge transfer to consider in more depth processual concerns. Through the accounts of Chinese MBA graduates and through the lens of liminality, this study has uncovered some of the unsettling, ambiguous yet creative aspects of the MBA experience as an exploratory 'in-between' phase. In so doing, we have added to existing accounts of the experiences and attributes of liminality as well as opening up further avenues of research in relation to the outcomes of the MBA. In terms of the former, the possibility and experience of a differentiated and hierarchically arranged liminal space as well as the blurring of boundaries between the liminal and post-liminal phase may resonate in other contexts and inform future research. With respect to the latter, work on MBA outcomes may usefully go beyond assessments of the relevance of programmes to the business world to consider the implications of 'in between' spaces for identities, development and change. 


\section{References}

Ahlstrom, D., Bruton, G. and Chan, E. (2001) 'HRM of Foreign Firms in China: The Challenge of Managing Host Country Personnel', Business Horizons 44 (3): 59-60.

Bryans, P. and Mavin, S. (2003) 'Women Learning to Become Managers: Learning to Fit in or Play a Different Game. Management Learning 34: 111-134

Chia, R. (1996) Teaching Paradigm Shifting in Management Education: University Business Schools and the Entrepreneurial Imagination, Journal of Management Studies, Vol. 33, No.4, pp.409-428.

Choo, K. L. (2007) The Implications of Introducing Critical Management Education to Chinese Students in UK business Schools: Some Empirical Evidence, Journal of Further and Higher Education, vol 31 (2) May 2007, 145-158

Clegg, S., Kornberger, M. and Rhodes, C. (2004) 'Noise, Parasites and Translation: Theory and Practice in Management Consulting', Management Learning, 35 (1): 3144

Czarniawska, B. and Mazza, C. (2003) 'Consulting as Liminal Space', Human Relations 56 (3): 267-290

Eriksson-Zetterquist, U. (2002) 'Gender Construction in Corporations', in B. Czarniawska and H. Hopfl (eds) Casting the Other: Production and Maintainence of Inequality in Organizations, pp. 89-103. London Routledge.

Garsten, C. (1999) 'Betwixt and Between: Temporary Employees as Liminal Subjects in Flexible Organizations', Organization Studies 20 (4): 601-617

Grey, C. (2002). 'What are Business Schools For?' Journal of Management Education 26: 496-511

Grey, C. (2004). 'Reinventing Business Schools: The Contribution of Critical Management Education'. Academy of Management Learning and Development, 3:178-187

Haight, T. and Kwong, K. (2000) 'Future of the MBA in China' Business Forum 24 $(1,2): 33-36$

Halford, S. and Leonard, P. (2006) Negotiating Gendered Identities at Work: Place, Space and Time. Palgrave MacMillan

Ituma, A., Simpson, R., Woods, A., Bo, X., Sturges, J. and Weight, P. (2007) 'Forms of Capital and Career benefits of the MBA in China and the UK', International Journal of Management Education 6 (2): 63-79

Kerfoot, D. and Knights, D. (1998). 'Managing Masculinity in Contemporary Organizational Life: A Man(agerial) Project'. Organization. 5/1: 7-26 
Knights, D. and McCabe, D. (2001). 'A Different World: Shifting Masculinities in the Transition to Call Centres'. Organization, 8: 619-645

Kretovics, M. (1999). 'Assessing the MBA What do our Students Learn?', Journal of Management Development 18 (2), 125-136

Leeming, A. and Baruch, Y. (1996). The MBA as a Bridge over the Troubled Waters of Discrimination'. Women in Management Review, 13 (3): 95-104

Lockett, M. (1988) 'Chinese Culture and the Problems of Chinese Management', Organization Studies 9 (4): 475-96

Massey, D. (2005) for Space, London: Routledge

McLean, G. and Shi, C. (2000) 'The Status of Training and Development in USPeople Republic of China Joint Ventures', Journal of Transnational Management Development, 5 (4): 41-68

Mezirow, J. (1991) Transformative Dimensions of Adult Learning. San Francisco, CA: Jossey-Bass

Mintzberg, H. and Gosling, J. (2002). 'Reality Programming for MBAs'. Strategy and Business 26 (1), 28-31

Ohlott, P., Ruderman, M. and McCauley, C. (1994). Gender Differences in Managers' Developmental Job Experiences, Academy of Management Journal. 37 (1), 46-67.

Pfeffer, J. and Fong, C. (2002). The End of Business Schools? Less Success than Meets the Eye, Academy of Management Learning and Education, 1 (1): 78-95

Pullen, A. (2006) Managing identity. London: Palgrave

Sinclair, A. (1995). Sex and the MBA. Organization, 2 (2): 295 - 317

Silverman, D. (1993) Interpreting Qualitative Data: Methods for Analysing Talk, Text and Interaction, London: Sage

Schrag, C. (1997) The Self after Postmodernity, New Haven: Yale University press

Shi, Y. (2000) 'A Status Report on MBA Education in China', International Journal of Education Reform, 9 (4) 328-334

Simpson, R. (2000). 'Winners and losers: Who Benefits Most from the MBA'. Management Learning, 31: 331-351 
Simpson, R. (2006) Masculity and Management Education: Feminizing the MBA, Academy of Management (Learning and Education) 5 (2): 182-193

Simpson, R., Sturges, J., Woods, A. \& Altman, Y. (2005). Gender Age and the MBA: An Analysis of Extrinsic and Intrinsic Career Benefits. Journal of Management Education 29: 218-247

Sinclair, A. (1995). 'Sex and the MBA'. Organization, 2: 295 - 317

Sinclair, A. (1997) The MBA through Women's Eyes: Learning and Pedagogy in Management Education, Management Learning 28 (3): 313-330

Sturdy, A. and Gabriel, Y. (2000) Missionaries, Mercenaries or Car Salesmen? MBA Teaching in Malaysia, Journal of Management Studies, 37 (7): 979-1002

Sturdy, A., Schwarz, M. and Spicer, A. (2006a) 'Guess who's Coming to Dinner? Structures and Uses of Liminality in Strategic Management Consultancy', Human Relations 59 (7): 929-960

Sturdy, A., Brocklehurst, M., Winstanley, D. and Littlejohns, M. (2006b) 'Management as a (Self) Confidence Trick: Management Ideas, Education and Identity Work', Organization 13 (6): 841-860

Sveningsson, S. and Alvesson, M. (2003). 'Managing Managerial Identities: Organizational Fragmentation, Discourse and Identity Struggle'. Human Relations, 56: $1163-1193$

Tang. J. and Ward, A. (2003) The Changing Face of Chinese Management, London: Routledge

Tjosvold, D and Ding, D. (2001) 'Management Training in China', Journal of Teaching in International Business 12 (2): 53-76

Tempest, S. and Starkey, K. (2004). 'The Effects of Liminality on Individual and Organizational Learning', Organization Studies, 25 (4): 507-527

Thomas, R. and Linstead, A. (2002). 'Losing the Plot: Middle Managers and Identity'. Organization, $9: 71-93$

Tomlinson, F. and Egan, S. (2002) Organizational Sensemaking in a Cultrually Diverse Setting: Limits to the 'Valuing Diversity' Disourse, Management Learning Vol 33 (1): 79-97

Turner, V. (1977) The Ritual Process, Ithaca NY: Cornell University Press

Turner, V. (1982) From Ritual to Theatre: The Human Seriousness of Play, New York: PAJ Publications 
Wahlin, N. (2006) 'Transcultural Encounters in Cities: Convergence without Becoming Coincident', in S. Clegg and M. Kornberger (eds) Space, Organization and Management Theory, Liber and Copenhagen Business School Press

Watson, T. (2001). 'Beyond Managism: Negotiated Narratives and Critical Management Education in Practice’. British Journal of Management, 12: 385-396

Welsch, W. (1999) 'Transculturality - the Puzzling Forms of Cultures Today' in Mike Featherstone and Scott Lash (eds) Spaces of Culture: City, Nation, World, 194-213.

London: Sage

Whitehead, S. (2001). 'Woman as Manager: A Seductive Ontology'. Gender Work and Organization, 8/1: 84-107 